\title{
NS34A resistance-associated substitutions in chronic hepatitis $C$ in Upper Egypt and regression of liver fibrosis after direct- acting antiviral therapy
}

Nahed A. Makhlouf ${ }^{1}$, Mohamed Farouk ${ }^{2^{*}}$ (D, Hanan Mohamed Nafeh', Ahmad Farooq Alsayed Hasanain ${ }^{1}$, Mohamed Ahmed El-Mokhtar ${ }^{3}$, Helal F. Hetta ${ }^{3}$, Mohamed A. Mekky ${ }^{1}$, Mohamed Alboraie ${ }^{4}$, Hussein ELamin ${ }^{2,5}$ and Ahmed Medhat Nasr ${ }^{1}$

\begin{abstract}
Background: Viral resistance-associated substitutions (RASs) can develop in the setting of DAAs therapy (i.e., emerging RASS). Long-term monitoring of fibrosis regression after achieving SVR to simiprevir (SMV)/sofosbuvir (SOF) is essential. The aim of this study was to determine the prevalence of baseline and emerging NS34A RASs in chronic HCV patients in Upper Egypt and to assess the impact of SMV/SOF therapy on liver stiffness.

Results: The enrolled 59 patients had HCV genotype 4a without any baseline RASs in the NS34A region. 96.6\% (57/ 59) of patients achieved sustained virological response (SVR12). Of the two patients who failed to achieve SVR12, one of them developed emerging RASs Q80K in the NS34A region. Seventy-two weeks after SMV/SOF therapy, the percentage of patients with liver fibrosis stage (F2, F3, and F4) decreased from $75.4 \%$ before treatment to $42.1 \%$ after treatment. The combination of SOF and SMV appeared to be well tolerated.
\end{abstract}

Conclusions: All patients had HCV genotype 4a without any baseline RASs in the NS34A region. In addition, there was improvement of non-invasive measures of liver fibrosis in patients who achieved SVR, 72 weeks after SMV/SOF therapy.

Keywords: SMV/SOF, RASs, Fibrosis regression, HCV

\section{Background}

In Egypt, the seroprevalence of hepatitis $\mathrm{C}$ virus (HCV) infection was about $10 \%$ in 2015. Since HCV infection is the main cause of liver cirrhosis, hepatocellular carcinoma (HCC), and liver transplantation globally, those patients with $\mathrm{HCV}$ are in a need for effective antiviral therapy to overcome the progression to these complications and to reduce mortality $[1,2]$.

HCV is a small, 9500-nucleotide, plus-stranded ribonucleic acid (RNA) virus that replicates in the cytoplasm

\footnotetext{
* Correspondence: dr.mfarouk.git@hotmail.com

${ }^{2}$ Assiut Center for Management of Viral Hepatitis, Assiut 71515, Egypt

Full list of author information is available at the end of the article
}

with a single open reading frame. The plus-stranded viral RNA is first translated into a large polyprotein containing about 3000 amino acids which is then cleaved by host and viral proteases into structural and nonstructural proteins [3].

Directly acting antivirals (DAAs) were designed to directly inhibit viral enzymes and proteins. The NS proteins NS3/4A protease-helicase and NS5B and the NS5A protein all perform crucial activities for the viral life cycle and by far have been the favorite targets for the development of new DAAs [4]. Sofosbuvir (SOF) is a pyrimidine nucleotide analog inhibitor of NS5B and simeprevir (SMV) is an NS3/4A protease inhibitor [5, 6].

\section{Springer Open}

(-) The Author(s). 2021 Open Access This article is licensed under a Creative Commons Attribution 4.0 International License, which permits use, sharing, adaptation, distribution and reproduction in any medium or format, as long as you give appropriate credit to the original author(s) and the source, provide a link to the Creative Commons licence, and indicate if changes were made. The images or other third party material in this article are included in the article's Creative Commons licence, unless indicated otherwise in a credit line to the material. If material is not included in the article's Creative Commons licence and your intended use is not permitted by statutory regulation or exceeds the permitted use, you will need to obtain permission directly from the copyright holder. To view a copy of this licence, visit http://creativecommons.org/licenses/by/4.0/. 
The high rate of HCV replication allows rapid response to selective immune or drug-induced pressure, which may select for resistant variants [7]. Viral resistance-associated substitutions (RASs) have been detected in patients naïve in HCV treatment (i.e., preexisting, baseline RASs), and RASs can occur with DAAs therapy (i.e., emerging RASs). Natural polymorphism Q80K, responsible for the reduced response of $\mathrm{HCV}$ to protease inhibitor simeprevir, is the most studied RAS $[8,9]$.

A huge number of patients with advanced chronic liver disease are achieving sustained virological response (SVR), highlighting the importance of monitoring fibrosis regression. Non-invasive methods such as transient elastography (TE), Fib-4 index, and APRI score may be useful for monitoring these changes [10,11].

According to recommendations of the National Committee for Control of Viral Hepatitis (NCCVH) in 2015 guided by recommendations of EASL 2015, 12 weeks of treatment with SMV/SOF combination therapy was recommended for patients with chronic HCV genotype4 [12]. Till the time of our study conduction, reallife data regarding the safety profile, tolerability, and effectiveness of SMV/SOF combination therapy in chronic HCV patients in Upper Egypt were still limited.

The aims of the work are (1) to determine the prevalence of baseline and emerging NS34A RASs in chronic HCV patients in Upper Egypt and (2) to assess the impact of SMV/SOF combination therapy on liver stiffness in patients with chronic $\mathrm{HCV}$ infection.

\section{Methods}

It was a prospective, open-label study that was conducted at the National Center for the Management of Viral Hepatitis. It took about 2 years' duration, from 1st of December 2015 to 30th of November 2017. All patients were subjected to detailed medical history, complete clinical examination, abdominal ultrasonography, fibroscan examination, routine laboratory investigations, AST to Platelet Ratio Index (APRI) score, and Fibrosis-4 (Fib-4 index) (in addition to HCV RNA PCR, $\mathrm{HCV}$ genotyping, and RAS testing).

Fibroscan examination was done at baseline and 72 weeks after the end of treatment. Fifty-nine patients with chronic $\mathrm{HCV}$ infection with and without compensated cirrhosis were enrolled.

The study population received a 12 -week regimen of simeprevir $150 \mathrm{mg}$ (Olysio ${ }^{\circ}$ produced by Janssen company) in combination with sofosbuvir $400 \mathrm{mg}$ (Sovaldi ${ }^{\circ}$ produced by Gilead Sciences company) once daily, in treatment-naïve or INF-experienced patients. The cost of this combination therapy was about 4000 L.E per month for each patient, and it was covered by the Egyptian government as a part of the national campaign for eradication of $\mathrm{HCV}$ in Egypt held by the National Committee for Control of Viral Hepatitis, The Egyptian Ministry of Health. Patients were advised to avoid sun exposure and to use sunscreen cream locally on sunexposed areas as possible. Patients also were advised not to take any other medication for any comorbidity without our consultation to check for drug-drug interactions.

\section{Molecular investigations}

PCR, sequencing for genotyping, and amplification of NS34A were carried out in the Medical Research Center, Faculty of Medicine, Assiut University, and in Macrogen Korea Laboratory, South Korea. SVR12 is sustained virological response with HCV RNA negative at 12 weeks after the end of therapy.

APRI score [13] and Fib-4 index [14] were calculated at baseline and 12 weeks after the end of therapy (EOT).

Fibroscan examination was performed in the Assiut Center for Management of Viral Hepatitis. The median value of ten successful measurements was considered representative of the liver stiffness (LS), according to the manufacturer's recommendations (IQR less than 30\% of the median value and success rate of more than 60\%) [15]. Based on the baseline LSM, patients were stratified according to estimated METAVIR fibrosis score into F0, F1, F2, F3, and F4 groups. Liver stiffness measurement (LSM) was used to estimate the METAVIR fibrosis stage as follows: F1 $\geq 6.5 \mathrm{kPa}$ [16], F2 $\geq 7.1 \mathrm{kPa}, \mathrm{F} 3 \geq 9.5 \mathrm{kPa}$, and $\mathrm{F} 4 \geq 12.5 \mathrm{kPa}[17]$.

\section{Statistical analysis}

Statistical tests were performed using SPSS 16.0 (SPSS Inc., Chicago, USA) for Windows. Results were reported as the absolute value, mean \pm standard deviation, and range. Continuous variables were compared using Student's $T$ test or Mann-Whitney $U$ test as appropriate. Nominal or ordinal variables were analyzed by the chisquare test and Fisher's exact test. $P<0.05$ was considered statistically significant. Variables with $p$ value $<0.05$ were then tested in a logistic regression model. The ability of Fib-4 index improvement in predicting LSM improvement was assessed by specificity, sensitivity, positive and negative predictive values, and positive and negative likelihood ratios, and accuracy was calculated.

\section{Results}

Table 1 shows the demographic and baseline data of the study group. All patients had HCV genotype 4a, and we did not find any baseline RASs in the NS34A region.

Table 2 shows virological response in the study group, where $96.6 \%$ achieved sustained virological response (SVR12). SVR was 96.3\% (52/54) in naïve patients and $100 \%(5 / 5)$ in INF experienced patients. Regarding patients who achieved SVR12, no one relapsed 72 weeks 
Table 1 Demographic and baseline data of the study group

\begin{tabular}{ll}
\hline Item & Descriptive \\
\hline 1. Age "years" mean \pm SD (range) & $50.66 \pm 9.80(27.0-69.0)$ \\
2. Sex: & \\
• Male & $41(69.5 \%)$ \\
3. BMI “kg/m" 2" mean \pm SD (range) & $27.84 \pm 4.42(19.4-39.1)$ \\
4. Diabetes mellitus: & \\
• Yes & $14(23.7 \%)$ \\
5. Treatment status: & \\
- Naïve & $54(91.5 \%)$ \\
- INF experienced & $5(8.5 \%)$ \\
6. HCV genotype & Genotype 4a (100\%) \\
7. Baseline NS34A RASs & $0(0 \%)$ \\
\hline
\end{tabular}

after the end of treatment (EOT). Patients with liver fibrosis F0-F2 (31/31) (100\%) achieved SVR (the two patients who did not achieve SVR12; one of them was F3 and the other was F4).

Of the two patients who failed to achieve sustained virological response, one of them developed emerging RASs Q80K in the NS34A region [sequencing analysis revealed that in this patient, the cytosine nucleotide was replaced by adenine at position 238 of the triplet, forming the amino acid number 80 , which resulted in the replacement of the glutamine $(\mathrm{Q})$ amino acid with lysine $(\mathrm{K})$ ], and the other patient did not have any emerging RASs in the NS34A region.

Table 3 shows changes in the laboratory data of the study group. There was a significant decrease in the mean values of alanine aminotransferase (ALT) and aspartate amninotransferase (AST) level after treatment at week 4, week 8 , at EOT, and 12 weeks after EOT (at SVR 12) $(p$ value $=0.001$ and $<0.001$, respectively) . There was no significant difference $(p$ value $>0.05)$ between the mean platelet count before treatment and after 4 and 8 weeks. However, there was a significant increase $(p$ value $<0.05)$ in the mean platelet count at EOT and at SVR 12. Regarding serum total bilirubin, there was a highly significant increase $(p$ value $=0.001)$ in serum total bilirubin at week 4 and week 8 of treatment compared to baseline. However, there was a significant decrease ( $p$ value $=0.001)$ in serum total bilirubin at SVR 12 compared to baseline. There was a significant decrease in the mean Fib-4 index and APRI score post-treatment when compared to pretreatment.

As shown in Table 4 and Fig. 1, after SMV/SOF therapy, patients with liver fibrosis stage (F2, F3, and F4) decreased from $75.4 \%$ before treatment to $42.1 \%$ after treatment and the total percentage of patients with liver fibrosis (F0 and F1) increased from 24.6 to $57.9 \%$.

Table 5 shows that the highest significant decrease in LSM, 72 weeks after EOT, was in patients with baseline liver fibrosis stage F2 and F3 ( $p$ value $=0.001)$. There was a significant difference between those with LSM improvement and those without LSM improvement, regarding treatment status before SMV/SOF therapy and Fib-4 index improvement status 12 weeks after EOT (at SVR 12) ( $p$ value $=0.042$ and 0.035 , respectively)

Multiple linear regression analysis showed that LSM improvement was significantly higher in patients who were naive and patients who showed Fib-4 index improvement after SMV/SOF therapy. The sensitivity of Fib-4 index improvement in predicting LSM improvement was $81.6 \%$ and specificity was $55.6 \%$. Its positive predictive value and negative predictive values were $88.6 \%$ and $41.7 \%$, respectively. The overall accuracy was $76.6 \%$.

Two patients suffered from headaches (3.4\%), two patients developed photosensitivity reactions (3.4\%), one patient developed bleeding gums (1.7\%), and one patient developed fatigue (1.7\%). Bilirubin level raised above 1.2 $\mathrm{mg} / \mathrm{dl}$ in 32/59 patients during SMV/SOF therapy with a percentage of $54.2 \%$. Among them, 9 patients (28\%) raised to a level above or equal to $2 \mathrm{mg} / \mathrm{dl}$.

There was a significant difference between those who developed an increase in serum bilirubin to a level $\geq 2$ mg during SMV/SOF therapy and those who did not show this increase, regarding baseline platelet count and baseline LSM in kilo Pascal $(\mathrm{kPa})$. Multiple linear regression analyses showed that the degree of rising in serum bilirubin levels significantly increased in patients who had higher baseline LSM (kPa). Six patients out of 9 (66.7\%), whose bilirubin levels were elevated to a level equal to or above $2 \mathrm{mg} / \mathrm{dl}$ after receiving SMV/SOF combination therapy, had liver fibrosis F4.

Table 2 Virological response in the study group

\begin{tabular}{llll}
\hline Item & F3, F4 & F0-F2 & Total \\
\hline Response: & & & $57(96.6 \%)$ \\
• Patients who achieved SVR12 & $92.9 \%(26 / 28)$ & $100 \%(31 / 31)$ & $2(3.4 \%)$ \\
• Patients who did not achieve SVR12 & $7.1 \%(2 / 28)$ & $0(0 \%)$ & $0.001 *$ \\
$\boldsymbol{p}$ value & $0.001 *$ & $\mathrm{NA}$ & \\
\hline
\end{tabular}

Total number $=59$ patients

NA not applicable, SVR12 sustained virological response with HCV RNA negative at 12 weeks after the end of therapy

* Statistically significant 
Table 3 Changes in the laboratory data of the study group

\begin{tabular}{|c|c|c|c|c|c|c|}
\hline Variable & ALT & AST & PLT & Bilirubin & Fib-4 & APRI \\
\hline Baseline & $44.86 \pm 21.34$ & $51.41 \pm 22.95$ & $195 \pm 68$ & $0.93 \pm 0.40$ & $2.42 \pm 1.69$ & $0.821 \pm 0.08$ \\
\hline 4 weeks & $25.19 \pm 9.07$ & $32.46 \pm 11.93$ & $196 \pm 66$ & $1.29 \pm 0.69$ & & \\
\hline Percent of change & $-43.84 \%$ & $-36.86 \%$ & $0.41 \%$ & $38.7 \%$ & & \\
\hline$p$ value & $0.001^{*}$ & $0.001^{*}$ & ns & $0.001^{*}$ & & \\
\hline 8 weeks & $23.46 \pm 9.33$ & $27.64 \pm 10.91$ & $207 \pm 74$ & $1.26 \pm 0.64$ & & \\
\hline Percent of change & $-47.70 \%$ & $-46.23 \%$ & $5.80 \%$ & $35.48 \%$ & & \\
\hline$p$ value & $0.001^{*}$ & $0.001^{*}$ & ns & $0.001^{*}$ & & \\
\hline 12 weeks (EOT) & $26.68 \pm 7.96$ & $29.03 \pm 7.14$ & $215 \pm 52$ & $0.98 \pm 0.44$ & & \\
\hline Percent of change & $-40.52 \%$ & $-43.54 \%$ & $10.11 \%$ & $5.37 \%$ & & \\
\hline$p$ value & $0.001^{*}$ & $0.001^{*}$ & $0.05^{*}$ & ns & & \\
\hline 12 weeks after EOT (SVR 12) & $24.46 \pm 7.63$ & $29.53 \pm 6.61$ & $218 \pm 64$ & $0.77 \pm 0.20$ & $1.60 \pm 0.61$ & $0.407 \pm 0.08$ \\
\hline Percent of change & $-45.47 \%$ & $-42.55 \%$ & $11.67 \%$ & $-17.2 \%$ & $-33.88 \%$ & $-50.42 \%$ \\
\hline$p$ value & $0.001^{*}$ & $0.001^{*}$ & $0.05^{*}$ & $0.001^{*}$ & $0.001^{*}$ & $0.027^{*}$ \\
\hline
\end{tabular}

Data were expressed as mean \pm standard deviation

Percent of change $=[($ variable 12 weeks after EOT - variable at baseline $) /$ variable at baseline $] \times 100$

All $p$ values compared the changes in the mean value of each parameter at a certain time in relation to the baseline, *Highly statistical significance

EOT endo of treatment, SVR12 sustained virological response with HCV RNA negative at 12 weeks after the end of therapy, ns not statistically significant

\section{Discussion}

HCV genotype 4a has been reported as the predominant subtype in Egypt in some studies [18-20]. In a study conducted in Damietta, El-Tahan et al. [21] found that HCV genotype 4a represents $93.3 \%$ (28/30) and genotype 1 represents $6.7 \%(2 / 30)$. However, we found that all 59 patients were infected with genotype 4 a without any baseline RASs at NS34A regions that reflect the high prevalence of HCV genotype 4a in Upper Egypt and the absence of baseline RASs in NS34A regions in Egyptian chronic hepatitis $\mathrm{C}(\mathrm{CHC})$ patients, and this is unlike other regions in the world, whereas the prevalence of Q80K in HCV genotype 1 in North America was 34\% [9]. To the best of our knowledge, we had conducted the first study that reported the prevalence of baseline NS34A RASs in patients treated with DAAs in routine clinical practice in Upper Egypt.

In the present study, the virological response agrees with the results of another study conducted by ElKhayat et al. [22] who assessed SVR12 for 583 Egyptian

Table 4 Fibrosis stage before and 72 weeks after SMV/SOF therapy in SVR patients

\begin{tabular}{llll}
\hline $\begin{array}{l}\text { Liver fibrosis } \\
\text { stage }\end{array}$ & $\begin{array}{l}\text { Before treatment } \\
\text { (baseline) }\end{array}$ & $\begin{array}{l}\text { 72 weeks after } \\
\text { treatment }\end{array}$ & $\boldsymbol{P}$ value \\
\hline F0 & $10(17.5 \%)$ & $20(35 \%)$ & $0.001^{*}$ \\
F1 & $4(7 \%)$ & $13(22.9 \%)$ & $0.001^{*}$ \\
F2 & $17(29.8 \%)$ & $7(12.3 \%)$ & $0.001^{*}$ \\
F3 & $10(17.5 \%)$ & $2(3.5 \%)$ & $0.001^{*}$ \\
F4 & $16(28.2 \%)$ & $15(26.3 \%)$ & $\mathrm{ns}$ \\
\hline
\end{tabular}

Total cases $=57$

*Statistically significant patients with $\mathrm{HCV}$ genotype 4 infections after receiving SMV/SOF without ribavirin for 12 weeks, and the SVR12 rate in their study was $95.7 \%$ and was lower among cirrhotic patients (80.8\%). Our results are also consistent with a study conducted by Eletreby et al. [23] who revealed the SVR12 rate achieved among a cohort of 6211 patients with genotype $4 \mathrm{HCV}$ infection was 94\%. Besides, we found that patients who achieved SVR12 were still a viremic 72 weeks after EOT.

RAS testing was done in the two patients who did not achieve SVR, and this revealed the presence of Q80K RAS in one patient (50\%). Due to the small number of patients who did not achieve SVR12, only two patients, we could not discover the possible predictors of the development of emerging NS34A RASs. We just observed that the female patient who developed Q80K after SMV/SOF therapy had leucopenia at baseline [TLC $($ Total leucocytic count $)=2.5 \mathrm{~K} / \mathrm{cm}$ ] while the other male patient who did not develop Q80K had normal TLC $(4.5 \mathrm{~K} / \mathrm{cm})$.

ALT is a biochemical marker for hepatocyte injury. Persistent ALT elevation is associated with chronic hepatitis $\mathrm{C}$ progression and increased risk for cirrhosis and an indication for treatment [24]. In the present study, there was a highly significant difference between ALT levels before treatment versus the ALT level after treatment at week 4 , week 8 , EOT, and 12 weeks after EOT ( $p$ value $=0.001)$. These results agree with De Pace et al. [25] who found that AST and ALT decreased during therapy: baseline mean AST $=52(32-81) \mathrm{UI} / \mathrm{mL}$ and mean ALT $=52.5(34-83.2) \mathrm{UI} / \mathrm{mL}$ vs EOT AST $=$ $21(18-28) \mathrm{UI} / \mathrm{mL}$ and ALT $=17$ (13-24.2). These results show the rapid improvement of the inflammatory 


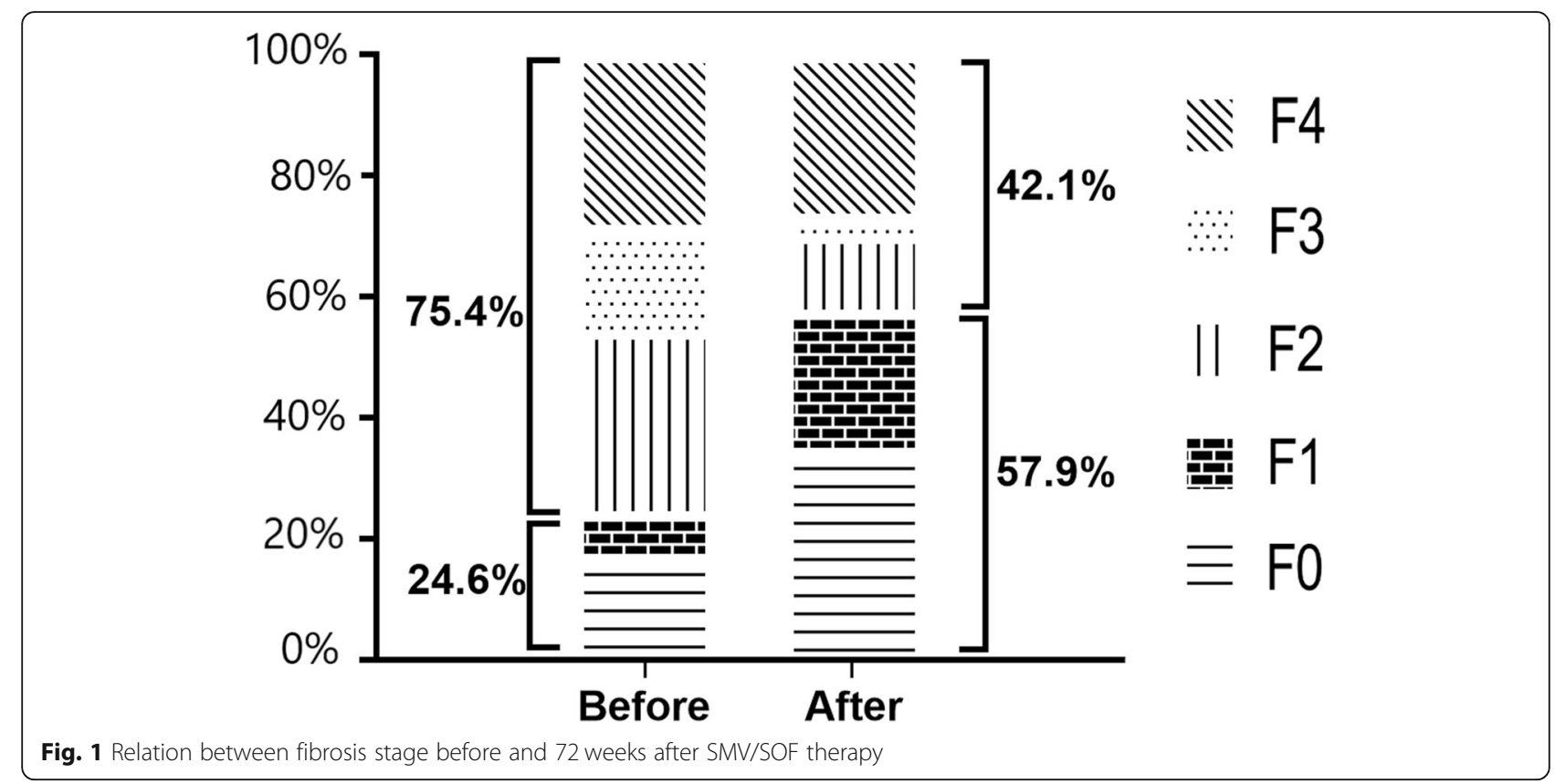

process and hepatocyte injury accompanying $\mathrm{HCV}$ infection.

Also, our study showed that non-invasive biomarkers of liver fibrosis as APRI score and FIB-4 index improved significantly in most of the patients. Unexpectedly, they improved in patients who did not achieve SVR. Also, we found that the possible predictors of APRI score improvement were lower baseline platelet, higher baseline AST, and higher baseline APRI score. In addition, we found that higher baseline AST was a possible predictor of Fib-4 index improvement. These results go in concordance with De Pace et al. [25] who found a significant dropping of APRI score and a moderate improvement in platelet values from baseline to EOT. In our study, platelet count increased significantly after treating patients with SMV/SOF combination therapy, and this agrees with Sayyar et al. [26]. Unexpectedly in our study, PLT count increased even in patients who did not achieve SVR.

Table 5 LSM before and 72 weeks after SMV/SOF therapy in SVR patients

\begin{tabular}{|c|c|c|c|}
\hline $\begin{array}{l}\text { Baseline liver } \\
\text { fibrosis stage }\end{array}$ & $\begin{array}{l}\text { Mean liver stiffness } \\
\text { before treatment } \\
\text { (baseline) }(\mathrm{kPa}) \text {, } \\
\text { mean } \pm \mathrm{SD}\end{array}$ & $\begin{array}{l}\text { Mean liver stiffness } \\
72 \text { weeks after } \\
\text { treatment }(\mathrm{kPa}) \text {, } \\
\text { mean } \pm \mathrm{SD}\end{array}$ & $P$ value \\
\hline $\mathrm{F} 1(n=4)$ & $6.4 \pm 0.5$ & $5.4 \pm 0.9$ & $0.088 \mathrm{~ns}$ \\
\hline $\mathrm{F} 2(n=17)$ & $8.5 \pm 0.5$ & $6.1 \pm 1.3$ & $0.001^{*}$ \\
\hline F3 $(n=10)$ & $10.7 \pm 0.7$ & $6.9 \pm 2$ & $0.001^{*}$ \\
\hline $\mathrm{F} 4(n=16)$ & $24.9 \pm 6.9$ & $20.7 \pm 5.6$ & $<0.05^{*}$ \\
\hline Total $(n=47)$ & $15.12 \pm 0.54$ & $10.27 \pm 0.97$ & $0.001^{*}$ \\
\hline
\end{tabular}

*Statistically significant
Lower baseline platelet count, higher baseline APRI score, Fib-4 index, lower baseline prothrombin, and higher baseline AFP (alfa-fetoprorein) were associated with the increased PLT (platelet) count after treatment. Nevertheless, linear regression analysis showed that lower baseline platelet count is the main predictor of the platelet count increase after treatment. This result may be explained by Amer et al. who studied the relation between platelet viral load and the possible response after antiviral therapy; low baseline platelet count and low platelet viral load may explain the better response in platelet count after antiviral therapy [27].

Amer et al. were investigating platelets as a possible reservoir of $\mathrm{HCV}$ and predictor of response to treatment, and they found that the platelet count tended to be lower among those with rapid virological response (RVR) compared to those with non-RVR throughout the follow-up. In addition, they found that among individuals with RVR, platelet counts declined slightly by week 4 and week 12 then gradually increased to reach pretreatment levels by week 48 , but there was no similar decline among patients who did not achieve RVR. Also, they found that platelet count remained almost constant over time, among non-SVR, but among SVR, it should have a steady small decline until week 12 , then it started to increase to pre-treatment levels, and also, they found that platelet counts did not correlate with platelet or serum viral loads or treatment responses [27].

Regarding the effect of antiviral therapy on the degree of hepatic fibrosis in our cohort, there was a significant difference between the degree of liver stiffness by fibroscan before and after therapy. According to literatures, a 
more accurate evaluation of fibrosis regression using fibroscan needs longer duration after EOT. Liver stiffness measurement can be influenced by inflammatory activity. Transient elastography improves within a short period of time following SVR, likely reflecting resolution of inflammation rather than regression of fibrosis. However, for patients evaluated at later time points postSVR, elastography appears to have good performance characteristics. Thus, delaying the post SVR assessment of liver stiffness for at least 1 year post SVR would seem prudent [28-30]. So we decided to choose a point of time which is of longer duration than 1 year for a better and more accurate evaluation of liver fibrosis regression.

Pons et al. [31] reported that the improvement of liver stiffness was found 4 weeks after starting DAAs therapy, which most probably reflects a reduction in inflammation rather than in fibrosis. We found that there was a significant difference between those patients who achieved liver stiffness improvement and those who did not achieve liver stiffness improvement regarding treatment status before treatment and the improvement occurring in the Fib-4 index after treatment. Patients who were naïve or who showed post-treatment Fib-4 improvement were more liable for improvement of LSM after SMV/SOF therapy. These parameters may be possible predictors of liver stiffness improvement.

Tag-Adeen et al. [32], in a study conducted in Qena University Hospital that enrolled $80 \mathrm{CHC}$ patients who received different DAAs regimens, found that LSM dropped from $15.6 \pm 10.8$ to $12.1 \pm 8.7 \mathrm{kPa}$ post-SVR; the maximum change of -5.8 occurred in $\mathrm{F} 4$ versus $2.79,-1.28$, and +0.08 in F3, F2, and F0-F1, respectively $(p<0.0001)$. Also, those patients showed significant improvement in the APRI score and Fib-4 index after achieving SVR. They found that younger age, male gender, raised baseline ALT, and raised AST were possible predictors of LSM improvement. Concerning the safety profile in this cohort, the combination of SOF and SMV appeared to be well tolerated in the majority of patients, where no deaths or serious side effects leading to the stoppage of the therapy had been reported. The incidence and degree of the adverse effects are comparable to those reported in the published international trials using the same regimen and with the same doses.

The safety profile seen in this study is in-line with the OPTIMIST-1 and OPTIMIST-2 studies [33]. Among the fifty-nine patients, minor clinical side effects as fatigue and bleeding gums were reported in one case for each (1.7\%). Headache and photosensitivity were reported in 2 patients for each (3.4\%). After EOT, all the dermatological manifestations gradually disappeared with a complete resolution with no residual sequels.

Raised bilirubin $>1.2 \mathrm{mg} / \mathrm{dl}$ was the most frequent adverse effect where it occurred in 32/59 (54.2\%). Total serum bilirubin level exceeded $2 \mathrm{mg} / \mathrm{dl}$ in nine patients $(9 / 59)(17.3 \%)$. This rise was reversible and the bilirubin level began to improve at week 8 of therapy, improved significantly at EOT, and returned to normal 12 weeks after EOT.

These findings came in agreement with the findings observed by El-Khayat et al. [22]; photosensitivity occurred in 18 patients among 583 patients (3\%) and hyperbilirubinemia occurred in 44 patients $(7.2 \%)$.

The current work had some limitations: (1) the small sample size was one of the drawbacks of the present cohort; (2) although the absence of baseline NS34A RASs is a good indicator of its low prevalence in Egypt, this made it difficult to study the effect of baseline NS34A RASs on the virological response after receiving the NS34A inhibitor-containing regimen (SMV/SOF combination therapy); (3) we could not study the efficacy of SMV/SOF combination therapy on other HCV genotypes because we found that all patients were infected with HCV genotype 4a only, although this is a good indicator of the high prevalence of genotype 4 in Egypt; and (4) another limitation is that our cohort is a Single Center Experience.

\section{Conclusions}

All patients had HCV genotype 4a without any baseline RASs in the NS34A region. One patient developed emerging RASs Q80K in the NS34A region. In addition, there was improvement of non-invasive measures of liver fibrosis in patients who achieved SVR, 72 weeks after SMV/SOF therapy.

\section{Abbreviations}

APRI: AST to Platelet Ratio Index; AST: Aspartate transferase; ALT: Alanine transferase; TLC: Total leucocytic count; LSM: Liver stiffness measurement; RASs: Resistance-associated substitutions; SIM/SOF: Simiprevir/sofosbuvir; SVR: Sustained virological response; EOT: End of therapy; HCV: Hepatitis C virus; RNA: Ribonucleic acid; DAAs: Directly acting antivirals; TE: Transient elastography; NCCVH: National Committee for Control of Viral Hepatitis

\section{Acknowledgements \\ The research team would like to thank all physicians and nurses in Assiut Center for Management of Viral Hepatitis and laboratory technicians in the Medical Research Center, Faculty of Medicine, Assiut University, and in Macrogen Korea Laboratory, South Korea, for their patience and their help during this study.}

\section{Authors' contributions}

MFA, MAM, and AFAH were responsible for data collection and were the operators of the fibroscan procedure. MA was the supervisor of the fibroscan procedure and analysis of its data. HFH and MAE were responsible of the laboratory testing including genotyping and RAS testing in collaboration with Macrogen Korea lab. NAM and HMN were responsible for writing and editing the manuscript. AMN and HE were the supervisors of the research work. All authors have read and approved the manuscript.

\section{Funding}

No funding.

Availability of data and materials

All data are available. 


\section{Ethics approval and consent to participate}

Reviewing the proposal was carried out before starting data collection via the ethical review committee of Assiut Faculty of Medicine. Privacy and confidentiality of all the data were assured. The aim of the study was explained to each participant before enrollment. Informed written consent was obtained from those who agreed to participate in the study. All patients were informed clearly that refusal of participation does not interfere with receiving the optimum available medical care.

The committee's reference number is not applicable and not available.

\section{Consent for publication}

All participants wrote consent for publication.

\section{Competing interests}

There was no conflict of interest.

\section{Author details}

'Department of Tropical Medicine and Gastroenterology, Faculty of Medicine, Assiut University, Assiut, Egypt. ${ }^{2}$ Assiut Center for Management of Viral Hepatitis, Assiut 71515, Egypt. ${ }^{3}$ Department of Microbiology and Immunology, Faculty of Medicine, Assiut University, Assiut, Egypt. ${ }^{4}$ Department of Internal Medicine, Al-Azhar University, Cairo, Egypt. ${ }^{5}$ Department of Internal Medicine, Faculty of Medicine, Assiut University, Assiut, Egypt.

\section{Received: 13 August 2020 Accepted: 18 January 2021}

\section{Published online: 01 February 2021}

\section{References}

1. Shawkat H, Yakoot M, Shawkat T, Helmy S (2015) Efficacy and safety of a herbal mixture (Viron ${ }^{\oplus}$ tablets) in the treatment of patients with chronic hepatitis C virus infection: a prospective, randomized, open-label, proof-ofconcept study. Drug Des Devel Ther 9:799-804

2. Elgharably A, Gomaa Al, Crossey MME, Norsworthy PJ, Waked I, TaylorRobinson SD (2017) Hepatitis C in Egypt - past, present, and future. Int J Gen Med 10:1-6

3. Lindenbach BD, Rice CM (2005) Unravelling hepatitis C virus replication from genome to function. Nature 436:933-938

4. Kayali Z, Schmidt WN (2014) Finally sofosbuvir: an oral anti-HCV drug with wide performance capability. Pharmacogenomics Pers Med 7:387-398

5. AASLD American Association for the Study of Liver Diseases/ IDSA: Infectious Diseases Society of America (2015) Hepatitis C guidance: AASLDIDSA recommendations for testing, managing, and treating adults infected with hepatitis C virus. Hepatology 62:932-954

6. Titusville NJ (2013) Janssen Therapeutics. Available from Drugs@FDA http:// www.accessdata.fda.gov/drugsatfda_docs/label/2017/205123s012lbl.pdf. Accessed 17 Feb 2017

7. Ahmed A, Felmlee DJ (2015) Mechanisms of hepatitis C viral resistance to direct acting antivirals. Viruses 7:6716-6729

8. Lawitz E, Sulkowski MS, Ghalib R, Rodriguez-Torres M, Younossi ZM, Corregidor A, DeJesus E, Pearlman B, Rabinovitz M, Gitlin N, Lim JK, Pockros PJ, Scott JD, Fevery B, Lambrecht T, Ouwerkerk-Mahadevan S, Callewaert K, Symonds WT, Picchio G, Lindsay KL, Beumont M, Jacobson IM (2014) Simeprevir plus sofosbuvir, with or without ribavirin, to treat chronic infection with hepatitis C virus genotype 1 in non-responders to pegylated interferon and ribavirin and treatment-naive patients: the COSMOS randomized study. Lancet 384:1756-1765

9. Sarrazin C, Lathouwers E, Peeters M, Daems B, Buelens A, Witek J (2015) Prevalence of the hepatitis C virus NS3 polymorphism Q80K in genotype 1 patients in the European region. Antiviral Res 116:10-16

10. Angulo P, Hui JM, Marchesini G, Bugianesi E, George J, Farrell GC, Enders F, Saksena S, Burt AD, Bida JP, Lindor K, Sanderson SO, Lenzi M, Adams LA, Kench J, Therneau TM, Day CP (2007) The NAFLD fibrosis score: a noninvasive system that identifies liver fibrosis in patients with NAFDL. Hepatology 45:846-854

11. Robic MA, Procopet B, Métivier S, Péron JM, Selves J, Vinel JP, Bureau C (2011) Liver stiffness accurately predicts portal hypertension-related complications in patients with chronic liver disease: a prospective study. J Hepatol 55:1017-1024

12. EASL; European Association for the Study of the Liver (2015) EASL recommendations on treatment of hepatitis C. J Hepatol 63:199-236
13. Borsoi Viana MS, Takei K, Collarile Yamaguti DC, Guz B, Strauss E (2009) Use of AST platelet ratio index (APRI Score) as an alternative to liver biopsy for treatment indication in chronic hepatitis C. Ann Hepatol 8:26-31

14. Kim BK, Kim DY, Park JY, Ahn SH, Chon CY, Kim JK, Paik YH, Lee KS, Park YN, Han KH (2010) Validation of FIB-4 and comparison with other simple noninvasive indices for predicting liver fibrosis and cirrhosis in hepatitis $B$ virus-infected patients. Liver Int 30:1073-1081

15. Lucidarme D, Foucher J, Le Bail B, Vergniol J, Castera L, Duburque C et al (2009) Factors of the accuracy of transient elastography (fibroscan) for the diagnosis of liver fibrosis in chronic hepatitis C. Hepatology 49:1083-1089

16. Tsochatzis EA, Gurusamy KS, Ntaoula S, Cholongitas E, Davidson BR, Burroughs AK (2011) Elastography for the diagnosis of severity of fibrosis in chronic liver disease: a meta-analysis of diagnostic accuracy. J Hepatol 54:650-659

17. Castéra L, Vergniol J, Foucher J, Le Bail B, Chanteloup E, Haaser M, Darriet M, Couzigou P. De Lédinghen V (2005) Prospective comparison of transient elastography, Fibrotest, APRI, and liver biopsy for the assessment of fibrosis in chronic hepatitis C. Gastroenterology 128:343-350

18. Ray SC, Arthur RR, Carella A, Bukh J, Thomas DL (2000) Genetic epidemiology of hepatitis C virus throughout Egypt. J Infect Dis 182:698-707

19. Youssef A, Yano Y, Utsumi T, Serwah A-H, Hayashi Y, Abd El-alah EM (2009) Molecular epidemiological study of hepatitis viruses in Ismailia, Egypt. Intervirology 52:123-131

20. Fakhr AE, Pourkarim MR, Maes P, Atta AH, Marei A, Azab M, Ranst MV (2013) Hepatitis C virus NS5B sequence-based genotyping analysis of patients from the Sharkia Governorate, Egypt. Hepat Mon 13(12):e12706

21. El-Tahan RR, Ghoneim AM, Zaghloul H (2018) 5' UTR and NS5B-based genotyping of hepatitis $C$ virus in patients from Damietta governorate. Egypt J Adv Res 10:39-47

22. El-Khayat HR, Fouad YM, Maher M, El-Amin H, Muhammed H (2017) Efficacy and safety of sofosbuvir plus simeprevir therapy in Egyptian patients with chronic hepatitis C: a real-world experience. Gut 66:2008-2012

23. Eletreby R, Elakel W, Said M, El Kassas M, Seif S, Elbaz T, El Raziky M, Abdel Rehim S, Zaky S, Fouad R (2017) Real-life Egyptian experience of efficacy and safety of Simeprevir/ Sofosbuvir therapy in 6211 chronic HCV genotype IV infected patients. Liver Int 37:534-541

24. Attar BM, Van Thiel DH (2016) Hepatitis C virus: a time for decisions. Who should be treated and when? World I Gastrointest Pharmacol Ther 7:33-40

25. De Pace V, Morelli MC, Ravaioli M, Maggi F, Galli S, Vero V, Re MC, Cescon M, Pistello M (2019) Efficacy, safety, and predictors of direct-acting antivirals in hepatitis $C$ virus patients with heterogeneous liver diseases. New Microbiol 42:189-196

26. Sayyar M, Saidi M, Zapatka S, Deng Y, Ciarleglio M, Garcia-Tsao G (2019) Platelet count increases after viral elimination in chronic HCV, independent of the presence or absence of cirrhosis. Liver Int 39:2061-2065

27. Amer A, Abu Madi M, Shebi FM, Al Faridi D, ALkhinji M, Derbala M (2016) Platelets as a possible reservoir of HCV and predictor of response to treatment. J Virol Antivir Res 5:3

28. Terrault NA, Hassanein TI (2016) Management of the patient with SVR. J Hepatol 65:120-129

29. Andersen ES, Moessner BK, Christensen PB et al (2011) Lower liver stiffness in patients with sustained virological response 4 years after treatment for chronic hepatitis C. Eur J Gastroenterol Hepatol 23:41-44

30. Hezode C, Castera L, Roudot-Thoraval F et al (2011) Liver stiffness diminishes with antiviral response in chronic hepatitis $C$. Aliment Pharmacol Ther 34:656-663

31. Pons M, Santos B, Simón-Talero M, Ventura-Cots M, Riveiro-Barciela M, Esteban R, Augustin S, Genescà J (2017) Rapid liver and spleen stiffness improvement in compensated advanced chronic liver disease patients treated with oral antivirals. Ther Adv Gastroenterol 10:619-629

32. Tag-Adeen M, Sabra AM, Akazawa Y, Ohnita K, Nakao K (2017) Impact of hepatitis $C$ virus genotype-4 eradication following direct-acting antivirals on liver stiffness measurement. Hep Med 9:45-53

33. Kwo P, Gitlin N, Nahass R, Bernstein D, Etzkorn K, Rojter S, Schiff E, Davis M, Ruane P, Younes Z, Kalmeijer R, Sinha R, Peeters M, Lenz O, Fevery B, De La Rosa G, Scott J, Witek J (2016) Simeprevir plus sofosbuvir (12 and 8 weeks) in hepatitis $C$ virus genotype 1-infected patients without cirrhosis: OPTIMIST-1, a phase 3, randomized study. Hepatology 64:370-380

\section{Publisher's Note}

Springer Nature remains neutral with regard to jurisdictional claims in published maps and institutional affiliations. 